\title{
RIMBAUD CUT-UP BURROUGHS
}

Mauricio S. Vasconcelos

$U F M G$

\section{RESUMO:}

O objetivo deste ensaio é o de explorar a relação entre a poesia de Rimbaud e as experiências de William Burroughs com os cut-ups. $A$ influência de Rimbaud sobre o trabalho de Burroughs se estende, contudo, para além dos cut-ups, envolvendo sua escrita ficcional. \section{PALAVRASCHAVE:}

Poesia Moderna, Fiç̧ão Contemporânea, Influência, Experimentação.

Ao estabelecer em seu importante estudo, The poetics of indeterminacy: Rimbaud to Cage, uma possível rede de influência da poesia de Rimbaud sobre a literatura americana, Marjorie Perloff faz menção aos escritos de Burroughs e Gregory Corso intitulados "Two cut-ups", publicados em 1961 na revista Locus solus, criados com os versos/frases de "À une raison". O contato de Burroughs com o poeta não terminará por aí. Embora, como se verá, a aproximação do universo de Rimbaud com o do autor de Naked lunch possa ser observada já neste segundo romance do escritor, publicado em Paris no ano de 1959, apenas a partir da realização dos cut-ups, datada deste mesmo ano, como se lê em sua biografia - El hombre invisible (A portrait), de Barry Miles -, é que Burroughs tornará explícito seu interesse pela obra do poeta francês. 
Quando expõe o método criativo oferecido pelos cut-ups, que têm origem nas pesquisas plásticas do artista Brion Gyson, o escritor utiliza-se dos textos de Rimbaud, ao lado dos de Shakespeare, como exemplos básicos de sua demonstração:

O método é simples. Eis um caminho para praticá-lo. Pegue uma folha de papel. Como esta página. Agora corte-a ao meio. Corte no meio das duas partes. Você tem quatro pedaços: $1234 \ldots$ um dois três quatro. Agora rearranje as partes colocando a parte quatro com a parte um e a parte dois com a três. E você tem uma nova página. Algumas vezes isso acaba dizendo a mesma coisa. Outras vezes, algo muito diferente - o recorte de falas políticas é um exercício interessante - em qualquer caso você acabará por considerar que isso diz alguma coisa $\mathrm{e}$ alguma coisa bem definida. Pegue algum poeta ou escritor de sua admiração. Poemas que você tenha lido muitas vezes. As palavras acabaram perdendo significação e vida através de anos de repetição. Agora pegue o poema e digite alguns trechos selecionados. Encha um papel com esses excertos. Agora corte a página. Você tem um novo poema. Como acontece com muitos poemas de Shakespeare Rimbaud, se você os aprecia. Tristan Tzara disse: "A poesia é para todos". E André Bréton chamou-o de policial, expulsando-o do movimento. Diga de novo: "A poesia é para todos". A poesia é um lugar, e livre para todos os cut-ups Rimbaud e você está no lugar de Rimbaud. Aqui está um Rimbaud poema cut-up.

Visita de memórias. Somente sua dança e sua casa de voz. Na atmosfera suburbana improváveis deserções...todo harmônico pinheiro a guerrear.

Os grandes céus estão abertos. Candura de vapor e tenda praguejando sangue riso e penitência bêbada.

Caminhada de perfume de vinho abre a lenta garrafa.

Os grandes céus estão abertos. Clarim supremo incendiando carne de crianças na neblina.'

Mais do que um exercício, um jogo com o aleatório, o método dos cut-ups representa um avanço nos planos da leitura e da escritá, pois seu objetivo

1. BURROUGHS, î78. p. $29-31$.
É produzir um pensamento efetivado por imagens, por processos analógicos, e não mais pelo circuito lógico-sintático imposto como primeira instância reflexiva pela linguagem. Embora se origine das colagens de Tristan Tzara, o cut-up de Brion Gyson e W. Burroughs expande e sistematiza o gesto iconoclasta e provisório do desconstrutor/destruidor cultural do início do século.

Os cut-ups estabelecem novas relações entre imagens, e o nosso campo de visão conseqüentemente se expande (...) os cut-ups tornam explícito um processo psico-sensorial que está acontecendo o tempo todo de qualquer jeito. (...) Eu estava sentado numa lanchonete em Nova York tomando meu café com roscas. Estava pensando que a gente realmente se sente um pouco encaixotado em Nova York, como que vivendo numa série de caixas. Olhei pela janela e lá estava um grande caminhão de mudanças. Isso é um cut-up - uma justaposição do que está acontecendo fora com o que você está pensando. Faço disso uma prática quando ando pela rua. Digo: Quando cheguei aqui vi aquela placa, eu estava pensando nisso, e quando volto para casa datilografo tudo isso. Uma parte desse material eu uso e outra não. Tenho literalmente milhares de páginas com anotações aqui, cruas, e mantenho um diário também. Num certo sentido isso é viajar no tempo. ${ }^{2}$

Torna-se potencializada pela prática dos cut-ups uma sensibilidade que opera por conexões, aproximando todos os níveis possíveis de informação - dos mais imediatos aos mais recuados no tempo e no espaço -, passando tudo a possuir significação e um sentido ativo de presentificação.

A maioria das pessoas não vê o que está acontecendo à sua volta. Esta é a minha principal mensagem para os escritores. Pelo amor de Deus, mantenham seus olkos abertos. Percebam o que está acontecendo à sua volta. ${ }^{3}$

Burroughs não trabalha apenas com recortes, colagens, fazendo a tesoura desempenhar uma verdadeira e substancial função de corte sobre a mesa de montagem do escritor, mas também com o gravador, a máquina fotográfica,
2. BURROUGHS, 1988. p. 142-143.

3. Idem. p. 143 . 
a still camera..., podendo a partir daí outras possibilidades técnicas e tecnologicas ser acrescentadas.

O método cut-up traz aos escritores a colagem, que tem sido usada pelos pintores há quarenta anos. E usada pela câmera de filmar e pela still. De fato todas as tomadas de rua feitas por filmadoras e pela still são guiadas por fatores ligados aos transeuntes e a justaposições cutups. Os fotógrafos dirão a você o mesmo. O melhor escrito parece ter sido feito quase por acidente até que o método cut-up tenha se tornado explícito - toda escrita são na verdade cut-ups. ${ }^{4}$

A técnica de escrita desnvolvida por Burroughs de modo mais demonstrativo na trilogia de romances (The soft machine/The ticket that exploded/ Nova express) publicada nos anos 60, busca explorar todo o campo da consciência, abrangendo as zonas de indeterminação não cobertas pela linguagem. A escrita cut-up abre-se também para o acaso de relações não estabelecidas com outros planos culturais, e outros de ordem cotidiana, vivencial, que impregnam a feitura e o resultado final do texto. Não se trata de uma filosofia da composição - como a de Poe -, na qual o controle da consciência do criador sobre o escrito pretende-se completo até o abarcamento do "inomeável". O método de Burroughs funda-se, ao contrário, sobre um diálogo sistemático com os processos não-conscientes, o que não deixa de soar como uma ampliação da "filosofia" composicional de Poe, sendo mesmo possível ler a produção dos cut-ups como uma espécie de síntese entre a atividade prática e analítica do autor de Gordon Pym e a "Alchimie du Verbe", de Rimbaud. Nota-se, contudo, que a técnica desenvolvida por Burroughs vai provocar o rompimento com a idéia de autoria absoluta, pela forma com que, entendendo a rede ilimitada de informação na qual se estabelece a atividade criadora, é considerado impossível a qualquer texto ganhar espaço no mundo, se não produz o seu corte/recorte sobre o já existente. Neste sentido, a literatura (como já disse ele em entrevistas) deve ser compreendida como um grande intertexto, ou melhor dizendo, um grande cut-up.

Os escritores supõem que liberam palavras - não para encadeá-las em frases. Quem disse que eles são poetas, tal como o supõem? Poetas querem dizer cantar e fazer cantar palavras. Poetas não têm palavras

4. BURROUGHS, 1978. p. 29. "de sua propriedade". Escritores não têm suas próprias palavras. Desde quando palavras pertencem a alguém? "Suas palavras próprias", de fato! E quem é você?

O escritor faz uma reescrita de Rimbaud, que é como deve ser entendida hoje uma leitura produtiva do poeta. Como se nota em Illuminations, a forma fragmentária e o dado combinatório comparecem, linha por linha, reforçando a função da imagem em sua poesia como prática desembaraçada de um simples código linguístico, incorporando gestos, música e movimentos sempre presentificados, que contêm já a descentralização e a amplitude características dos cut-ups. Isso para não se falar do "decalque paródico", da descontextualização, com respeito ao legado romântico e parnasiano, trabalhados desde "Les étrennes des orphelins" até a folia intertextual do Cercle Zutique.

Shakespeare Rimbaud vivem através de suas palavras. Corte linhas de palavras e você ouvirá suas vozes. Os cut-ups vêm muitas vezes através de mensagens codificadas com significados especiais para aquele que recorta (the cutter) (...) Toda escrita é, na verdade, feita por cutups. Uma colagem de palavras lidas, ouvidas, reouvidas. O que mais? $\mathrm{O}$ uso da tesoura torna este processo explícito e sujeito à extensão e à variação. A prosa clara clássica pode ser composta inteiramente de cutups rearranjados. O corte e o rearranjo de uma página de palavras escritas introduz uma nova dimensão à escrita habilitando o escritor a modular imagens numa variação fílmica. Imagens projetam sentido sob o corte da tesoura imagens de odor da visão ao som do som à cinestética. Por esta dimensão é que foi Rimbaud com a sua cor das vogais. E seu "sistemático desregramento dos sentidos".

"Derangement/arrangement", a capacidade de ser a escrita uma arte de operar conexões, a contar com o descentramento do autor em seu sempre surpreendente encontro com a rede analógica das imagens do mundo, mostra a grande afinidade de Burroughs com o "não-método" encampado por Rimbaud em "Alchimie du verbe", e aplicado integralmente em Illuminations. Em Rimbaud, mostra-se visceral esta disponibilidade combinatória, pela qual ele

\section{Idem. p. 34.}

6. Idem. p. 32. 
extrai imagens de outras imagens, assim como cores e atributos não-determinados de átomos verbais/sonoros como as vogais. O que chamou de "hallucinations simples" já contêm os germes dos cut-ups em sua lógica relacional feita de palavras/imagens justapostas, que Rimbaud recolhe do repertório cotidiano, assim como daquele arsenal entendido como "vieillerie poétique" (ibid.), celebridades "de la peinture et de la poésie moderne".'

Lê-se na "Alquimia" a eclosão auto-referencial da cultura, por força da utilização feita pelo autor do próprio material poético incluído no corpo experimental do poema-prosa. Para ele a onipresença autoral já passa a sofrer seus primeiros deslocamentos na busca do "lugar e da fórmula" ("Vagabonds") de um verbo poético "acessivel a todos os sentidos"("Alchimie du Verbe"). Entretanto, não só na "Alquimia do Verbo" Rimbaud revela esta disposição intrínseca aos choques/contatos de várias fontes de informação e pontos-devista. Como se observa em Illuminations, o papel que a informação (jornalística, turística, topográfica, arquitetônica, urbanística....) atua sobre os textos é significativo. Já em "Bateau ivre," Augusto Meyer ${ }^{8}$ fazia notar como o Magasin Pittoresque, espécie de National Geographic da época, era apropriado pela aventura náutica do poeta. Já existe da parte de Rimbaud a sensibilidade informacional, que vai nortear o trabalho de Burroughs no sentido da estocagem (em suas reflexões sobre a escrita e os cut-ups ele esclarece sobre o uso de arquivos de textos, imagens e tapes) e da circulação de dados criativamente combinados.

Como afirma Burroughs, a feitura dos cut-ups não atende simplesmente a justaposições ocasionais de palavras, mas intervém na ordem da percepção e também da imaginação. $O$ escritor torna-se mais próximo de seu meio de expressão, pondo-se em uma comunicação viva, tátil, e não mais indireta, como aquela oferecida pela linguagem em suas abstrações, sua "prisão" de palavras. Estas passam a se apresentar como substância manuseável, trabalhadas para além da mera organização métrica/sintática de um raciocínio verbal, integrando-se de forma atuante a um campo mais vasto do conhecimento.

A habilidade do pintor em tocar e vivenciar seu meio de expressão o orientou para as técnicas de montagem há sessenta anos atrás. Aguardase que a extensão das técnicas dos cut-ups conduzam a experimentos verbais mais precisos, na proximidade do vácuo de sentido, dando ao

\section{RIMBAUD, 1991. p. 429.}

B. MEYER, 1986. p. 40. vazio uma nova dimensão de escrita (...) Toda essa experimentação pode levar a uma ciência precisa das palavras, mostrando como certas combinações de palavras produzem certos efeitos...'

Extensão dos cut-ups, o the fold-in method, que consiste em dobrar um texto no outro - justaposição e não mais recorte -, tal como praticado em Nova express e The ticket that exploded, permite a Burroughs o que chama de viagem no tempo e no espaço:

Em minha escrita ajo como um construtor de mapas, um explorador de áreas físicas (...) como um cosmonauta do espaço interior, e não vejo nenhum interesse em explorar áreas que já tenham sido completamente avaliadas - Um cientista russo disse: "Não viajamos somente no espaço mas no tempo também" - Se os escritores estão capacitados a viajar no espaço-tempo e a explorar áreas abertas pela era espacial, penso que devem desenvolver técnicas tão novas quanto definidas como técnicas de viagem no espaço físico. Certamente se a escrita tem futuro deve, no mínimo, desvencilhar-se do passado e aprender a usar técnicas já usadas há muito tempo atrás na pintura, na música e no cinema.

O que leva o escritor a não escolher, a não editar e a não rearranjar o material à sua disposição? O método fold-in dá ao escritor literalmente um infinito campo de opção - Tome, por exemplo, uma págna de Rimbaud anexada, dobrada a uma outra de Saint-John Perse (os dois poetas têm muito em comum) - Dessas duas páginas um número infinito de combinações e imagens mostra-se possível - $O$ método poderá levar a uma colaboração entre escritores em uma escala sem precedentes de modo a produzir trabalhos que são um esforço compósito de um número de escritores vivos e mortos - Isso ocorre, de fato, tão logo qualquer escritor comece a usar o método fold-in. ${ }^{10}$

Em The ticket that exploded, William Burroughs dá continuidade aos projetos da walk-writing/escrita de caminhada praticada por Rímbaud ao longo de sua obra, e disposta na abertura de "Alchimie du verbe" como o sonho das

9. BURROUGHS, 1978. p. 27-28

10. Idem. p. $95-96$ 
cruzadas, "viagens de descobertas (...) deslocamentos de raças e de continentes"'। , mas já no espaço, através do recorte criativo das narrativas de science-fiction. As viagens projetadas pela carta de previsões e encantamentos que é a "Alchimie", efetivam-se agora com o americano Burroughs no espaçotempo de uma epopéia anti-modelar, mas viabilizada em total afinação com o que o escritor identifica como "space age"' . Nesse romance, publicado em 1962 também em Paris, onde passou a residir depois de vários acidentes relacionados à fase junky mais pesada, a narrativa é interrompida, ou, melhor dizendo, dimensionada, com um capítulo dedicado à writing machine. A máquina de escrever aparece dilatada e retorcida como um daqueles objetos vivos-animaissiderais construídos por David Cronemberg, recriador de Naked lunch no cinema, superdimensionada pelo uso dos cut-ups e pela elaboração de uma sci-fi. Materializa-se como aparelho dotado de alta frequência sonora-visual-escritural, por meio do qual são possíveis de se contemplar "vast mobile sculpters of Music/ vastas esculturas móveis de Música"13

Tal como ocorre em "Fleurs" e "Scènes", o capítulo "Writing machine" integra um espetáculo, definido como A Exibição.

A Exibição estendeu-se por muitas salas e corredores - Barracas foram destruídas em um jardim híbrido submerso e com terraço Piscinas e canais refletiam flores flutuantes (arranjos inextricavelmente mixados com pinturas de flores e jardins).

Em uma sala de muros metálicos magnéticos móbiles sob fosforescente luz azul e odor de ozônio - juventudes de metal conectadas em dança sob um chuveiro de jatos azuis, rodopiando juntamente em orgasmos trêmulos de metal - pedaços de papel caligrafias magnéticas desenhadas e coloridas limalhas de ferro caídas em nuvens de cor, indo de padrões pulsantes à música metálica, fora e dentro, fora e dentro.

Peças no palco com seções permutáveis moveram-se umas das outras Shakespeare, Grego antigo, balé. Filmes são mixados em uma tela metade uma metade outra - peças de frente para a tela de cinema sincronizadas de forma que cavalos se encaminham dentro e fora de

11. RIMBAUD, 1991.P. 429.

12. BURROUGHS OpUd SKERL \& LYONEBERG, 1991. p. $265-268$

13. BURROUGHS, 1966. p. 64 . velhos Westerns (...) Conversas gravadas de filmes realizadas durante a exibição aparecem na tela até que todos os espectadores estejam envolvidos - situações permutáveis e em movimento - ...14

Em "Fleurs", Antonio Candido havia considerado ser "perfeito o encontro do universo factício (cuja lei é a ordenação arbitrária de componentes convencionais) com o universo natural, porque a comparação que gera as imagens é feita como se o termo metafórico tivesse uma vida independente do termo metaforizado. Ou, por outra, como se a imagem se tornasse objeto convencional do mundo novo"15. Tal poder de autonomia, de projeção, adquirido pela imagem mostra-se mais intenso quando Burroughs revivifica as visões do poeta, ao inseri-las em um universo como o da fiç̧ão-científica, marcado pelo caráter de sondagem e de antecipação, que torna estreitos os laços entre arte $e$ ciência. Em Burroughs, a tecnologia acaba por conceder ao "universo factício", de que fala $\mathrm{A}$. Candido, seu lugar de natureza.

As imagens utilizadas de "Fleurs". referências a um terraço de flores aquáticas; um jardim exposto em toda sua magnificência natural e "construída" como exibição aos olhares dos leitores/espectadores-, de llluminations, tomadas como um todo - "Pratos antiquados tombam como neve luminosa suavemente caindo cabelo escuro cabelo de luz clicado mais fundo mais fundo no silêncio azul'16 - , reforçam o estatuto codificador de uma nova sensibilidade, que sem dúvida é um Mundo Novo - como Cânddo percebe no poema original -, admirável e também abissal, onde pulsa a "vida independente do termo metaforizado". The ticket that exploded redimensiona práticas de Rimbaud com a matéria literária e cultural de seu século, uma prática de escrita, no ver de Jacques Rancière:

... não se trata de ler mas de escrever. Rimbaud não leu as teorias do século, ele escreve o século que as une (...) Marca as coordenadas e estabelece todas as ligações possíveis entre elas no mesmo espaço. Tornao evidente e, ao mesmo tempo, ilegível. Mas ele faz isso acreditando, querendo fazer alguma coisa diferente. O que ele quer, com efeito, é passar à frente do século. Pretende dar a ele o que falta para terminar o projeto do novo corpo glorioso, uma língua: a língua do futuro, a do

\section{Idem. p. $62-64$ \\ 15. CAMOIDO, 1991. p. 1-2.}

16. BURROUGHS, 1964. p. 63. 
corpo integral, da comunidade das energias reunidas ("As vozes reconstituidas; o despertar fraterno de todas as energias corais $e$ orquestrais e suas aplicações instantâneas")."1

Esta postura escritural encontra equivalência em Burroughs na contemporaneidade, quando ele cultiva a linha máxima da imaginação, desentranhada de discursos e textos progressivos, científicos: conquistas espaciais para o escritor que faz da página o revés iluminado e a vertigem, também, do cosmos. E na pulsação de um tempo, que não é o da imagem de futuro estandartizada pela fíç̧ão científica.

Pode-se dizer que a literatura de Burroughs já viaja na velocidade da luz. No entanto, em acordo com a visão de Rimbaud nos poemas da série "Villes", "H", "Matinée d'ivresse" e "Promontoire" (e de outros pertencentes a Illuminations), não se nega lugar à explicitação do artifício - drogas, o imagismo civilizatório - e do controle contidos nas fosforescências ultra-modernas da tecnologia, onde a science-cut-up-fiction vislumbra traços não-utópicos. " $A L L$ IS POSSIBLE BECAUSE ISN'T TRUE", diz Burroughs em sua leitura/canção "Apocalypse", gravada no disco Dead city radio.

...um odor de dilúvio e coragem para deixá-lo ir - Ao ar livre um garoto está esperando - Sorrisos alcançam alguém caminhando - As perguntas se afundam vagarosamente fora de um velho sonho - vento da montanha tomado na porta - o odor de sóis afogados toma a trilha do suor na roupa de linho no instante do último macaco da história - Da maneira como eu gostaria de indagar sobre as alterações exceto o céu azul sobre nosso tíquete, que explodiu - ...

Escrita na porta pura informação - Coisa grande conversa policial em uma baixa condição, identidade se dissolvendo - luz giratória é tudo - faca de pão no coração tomba sobre o escuro amotinado corpo sem sombra - Cinco minutos de poeira foi tudo o que fizemos - Réplicas não dão abrigo - marca de poeira - $\mathrm{E}$ aqueles cães nada sabiam Circunstâncias na crueza que a noite te oferece? - ponha fogo na trilha - com esse cabelo de um sonhador sem cor - um arrumadinho bateu na porta com violência - solidão na manhã lavada de neon - os mortos da batalha deixaram uma mistura de amanhecer e sonho - dirigindo um boa noite sob ondas de silêncio flutuando dióxido de carbono - ${ }^{10}$

Da mesma forma que ele cria, a partir das "Fleurs" rimbaudianas, uma linguagem do encantamento para montar um jardim de delícias sexuais, vividas de modo público e desreprimido em um ambiente de alta-tecnologia, ele pode desestabilizar o organização da linguagem dentro do corpo, juntamente com seus sistemas psico-motores-sensoriais, em um gesto mais regressivo que progressivo, por meio do qual a origem e os limites do homo-sapiens se chocam do modo mais orgânico, mais brutal. Penso no seguinte relato, já tornado célebre pelo filme de Cronemberg, contado pelo Dr.Benway em Naked lunch:

Benway: ...Eu já te contei alguma vez a respeito de um homem que ensinou o cu dele a falar? A barriga inteira mexia para cima e para baixo, entende, peidando as palavras. Era algo diferente de tudo que eu já ouvira.

Esse papo do cu tinha uma espécie de freqüência visceral. Batia direto lá embaixo como você tem que ir. Sabe quando o velho cólon te dá uma cutucada e você sente um friozinho por dentro e sabe que tudo o que tem que fazer é se afrouxar? Bem, esse papo te batia exato ali embaixo, um som embolhado grosso estagnante, um som que você podia cheirar.

Esse cara trabalhava num circo, entende, e para começar era uma novidade como número de ventíloquo. Realmente engraçado, no começo. Ele fazia um número chamado "O Melhor Buraco" que era uma doideira, vou te contar. Eu me esqueço da maior parte, mas era muito inteligente. Algo como,

'Oh, você ainda está aí embaixo, coisa velha?'

'Nah! Eu tive que ir me aliviar.'

Depois de algum tempo o cu começou a falar por conta própria. Ele entrava em cena sem nada preparado e o cu improvisava, respondia as piadas com outras o tempo todo.

Aí o cu desenvolveu uma espécie de ganchinhos curvados e ásperos, à maneira de dentes, e começou a comer. Ele achou isso engraçadinho no início e bolou um número em torno da coisa, mas o cu abria um 
caminho através das calças e começou a falar na rua, berrando que queria igualdade de direitos. Tomava porres e tinha crises de choro que ninguém me ama, que queria ser beijado como qualquer boca. No final o negócio falava o tempo todo, dia e noite, você podia ouvi-lo por quarteirões berrando que o cu se calasse e batendo nele com o punho, e enfiando velas nele mas coisa nenhuma adiantava e o cu disse para ele: 'É você que vai se calar no fim. Não eu. Porque nós não precisamos mais de você por aí. Eu posso falar e comer e cagar.'

Depois disso ele começou a acordar de manhã com uma geléia transparente com um rabo de girino, por cima de toda a boca. Essa geléia era o que os cientistas chamam T.in-D, Tecido Indiferenciado, que pode crescer em qualquer tipo de carne do corpo humano. Ele a arrancava da boca e os pedaços se prendiam em suas mãos como gasolina gelatinosa queimando e crescendo lá, crescendo em qualquer lugar em que um pedaço caía. E finalmente sua boca se fechou, e a cabeça inteira seria amputada espontaneamente - (você sabe que existe uma condição que ocorre em partes da África e só entre negros, em que o dedo mínimo do pé se amputa espontaneamente?) - exceto pelos olhos, entende. Uma coisa que o cu não podia fazer era ver. Precisava dos olhos. Mas as ligações nervosas foram bloqueadas, infiltradas e atrofiadas para que o cérebro não pudesse dar mais ordens. Ficou preso no crânio, exilado. Por um momento você podia ver o sofrimento silencioso e indefeso do cérebro por trás dos olhos, até que finalmente ele deve ter morrido, porque os olhos se apagaram, e não havia mais sentimento neles que no olho de um caranguejo preso à ponta de uma haste. ${ }^{19}$

Nesta guerra entre boca e ânus - guerra dos órgãos, como define Laymert Garcia dos Santos, com base em Artaud, a "experiência da agonia" deflagrada para alcance de uma linguagem "que é ação do corpo, dos órgãos e dos sentidos" $"$, o corpo logocêntrico é violentamente alterado. A linguagem, que por efeito de uma hierarquização, assumia o controle da mente, acaba por mostra que o homem nada é sob o seu comando, ao sofrer a sublevação do corpo. A parábola cruel montada pelo escritor traz ecos de "Remembrences du

\footnotetext{
19. BURROUGHS, 1984. p. 123-124.
}

20. SANTOS, 1989. P. 23 vieillard idiot", no que o poema rimbaudiano revela sobre uma corporeidade involuntária e desregrada, da qual o sujeito desconhece o funcionamento, cada vez mais exilado de um organismo que o exaure até a idiotia. Com tintas ainda mais corrosivas, Burroughs é bem um cirurgião - ele volta e meia interpreta as falas e os gestos do Dr. Benway em leituras, filmes e performances - a bloquear os centros nervosos da linguagem, instaurando a presença física das palavras, desgarradas, então, de um sistema limitadamente binário em suas clássicas oposições entre mente/corpo, dentro/fora, consciente/inconsciente.

Ao romper com a diferenciação entre boca e ânus, entre ato e baixo atribuições que não são apenas de uma ordem física, mas também de valor -, ele instala a partir do corpo o contato com o que chamou Robin Lydenberg de "descorporificada, parasítica maquinaria do poder" ${ }^{21}$. Sendo compreendida a linguagem como presença imaterial, parasitária no corpo humano, Burroughs passa a expor "as anônimas e invisíveis forças que manipulam a vida individual". 22 Quando lembramos a famosa asserção de Foucault de que não falamos mas somos falados, ler a novelística de Burroughs é como penetrar na ventriloquia em que se constituem a linguagem e o pensamento humanos, para bem dentro dos circuitos de vozes desencorpadas e máquinas de controle abstrato, como aquelas possíveis de se personificarem como "Death Dwarfs"/"Anöes da Morte" em Nova express.

Conhecemos pela ficção científica do autor o embate, tal como descrito por Laymert, entre a voz imensa, cultural, e a voz mínima, gradativamente autonomizada por obra de uma guerra orgânica movida contra a linguagem, vírus, como definiu o autor de Naked lunch - sistema imposto de fora, mas alojado de forma interiorizada dentro de cada um. Combate "à morte em vida, como expressa Laymert, a partir de dentro, ao que é incapaz de manifestar a atividade fisiológica, a voz afirmativa do corpo. Robin Lydenberg notou a presença do "dérèglement de tous les sens..." em The ticket that exploded como passagem irrecusável para uma maior convivência, um maior entendimento com o corpo, do qual advém a conquista de uma dicção individualizada. Burroughs passa pela distopia, pela fala apocalíptica descerrada das novas polícias montadas no espaço, abrindo sempre um intervalo no interior da lingıagem, "porque sempre existe um espaço entre canções populares e filmes B ..."24

21. LYOENBERG, 1987. p. 138.
22. Idem.
23. SANTOS, 1989. p. 13.
24. 8URROUGHS, 1968. p. 133 .


Juntando o que não se juntava, cria-se uma terceira possibilidade Third mind, eis o título da obra escrita em parceria com Brion Gyson, na qual refletem sobre os cut-ups e outros métodos -, produto de um vácuo/intervalo da linguagem e do pensamento, nascido de uma relação íntima com o acaso, com o indetermiando. Como diz Burroughs no livro de entrevistas The job, os significados revelados pelo uso dos cut-ups podem se referir a acontecimentos futuros, estendendo a escrita ao plano da antecipação, ao ingresso nos níveis analógicos mais sutis de manifestação simbólica, favorecendo uma maior entrada no campo das imagens, e com isto uma atuação mais eficaz na existência.

Fica claro, entretanto, para o autor que esta atividade é extraída da "barragem absoluta de imagens às quais somos submetidos de modo a nos tornarmos embotados (...) se vocês são absolutamente bombardeados por imagens de caminhões em trânsito e carros e televisões e jornais vocês se tornam embotados e isso cria uma névoa permanente em frente dos olhos, de forma a não se poder ver mais nada"'25. $O$ aspecto visionário propiciado pela técnica dos cut-ups não elide, pois, a barragem, os pontos cegos, redundantes, em que se movem as imagens contemporâneas, diante das quais a identidade se espatifa a mercê do consumo e do controle. Lembro, porém, que tanto para Burroughs quanto para Rimbaud o mundo é dado como imagem e também como desrepresentação.

Assim como o poeta destilou a "velharia" das "celebridades modernas", o autor de Ticket that exploded abeirou-se da ficção do desastre e do apocalipse (assim como do manancial mass-media) para efetivar o trabalho alquímicocientífico da linguagem, por meio do qual despontam novas formações poéticas e suas conjugações políticas-eróticas-cósmicas. Entre Rimbaud e Burroughs há um vácuo de épocas e nacionalidades, entre o despontar e a agonia do moderno, mas estes extremos de espaço/tempo só se intensificam por ordem dos níveis mais sofisticados de imaterialidade e velocidade com que se produzem as imagens do mundo. Pois a intuição do autor francês a respeito da criação de um novo corpo, em sintonia com a busca de um verbo poético potencializado em todas suas dimensões relacionadoras e reveladoras, encontra eco no narrador americano.

Burroughs aproxima-se da linguagem com uma vigilante e científica imparcialidade. Tomando controle da palavra de modo a realizar uma espécie de dissecação cirúrgica de suas funções, ele tenta revelar e transcender os mecanismos de controle constituídos no interior de nosso sistema de linguagem (...) Suas intermitentes e utópicas fagulhas de liberação são baseadas nas remotas possibilidades de escapar do "corpo e da palavra" (...) gerando um corpo novo e liberado da manipulação das formas tradicionais de palavra, texto e carne. ${ }^{26}$

A promessa de um "novo corpo amoroso", nascido de "blessures écalartes et noires..." /"feridas escarlates e negras" ("Being Beauteous"), podemos ver reavivada nos romances americanos com toda sorte de violência "L'élégance, la science, la violence!", diz "Matinée d'ivresse" -, tanto voluntária quanto instituída: Carne Negra traficada pela Polícia do Sonho em Naked lunch. Através da incursão pelo inferno psicotrópico, pelos subterrâneos da mente, do corpo e da palavra, a escrita de Burroughs alcança o estado de uma linguagem/ música executada em dimensões sempre surpreendentes do espaço-tempo. Pois encontra-se conectada com o presente e com o sentido aguçado de cruzamento com as imagens - signos e sinais multivariados - do mundo. Está em sincronia, enfim, com o poder de revelar, e não apenas o de narrar, as forças, os embates vivos, que se realizam e desrealizam na extensão entre arte e ciência, imaginação e pensamento, ao compasso da atuação do "construtor de mapas ... explorador de áreas físicas ... cosmonauta do espaço interior".

Marcada pelo conflito, pela contundência, próprios à expulsão do vírus que parasitou o corpo criativo da linguagem, esta literatura experimenta técnicas e tecnologias de som (seu trabalho com tapes e leituras de texto compõem todo um capítulo à parte) e imagem, revelando seu autor como presença viva, performativa e essencial, como uma espécie de xamã high-tech da cultura americana. Em um raio de ação que vai da gravação de $C D s$, onde a leitura de seus textos passa por toda série de registro e experiência - como em Spare Ass Annie and other tales (1993), um disco feito a partir de sua voz, sob a "batida" rap do grupo Disposable Heroes of Hiphoprisy, ou em The "priest" they called him, gravação realizada, nas mesmas bases, com Kurt Cobain, guitarrista e lider do Nirvana, pouco antes de sua morte e da extinção da banda -, até longametragens que contam com sua participação como ator (Drugstore cowboy de Gus Van Sant), e um video-clip do grupo Ministry, no qual comparece como ele mesmo, realizando Shotgun Paintings (experiências plásticas envolvendo o uso de armas). Sem se falar que W.S.B. é a grande referência de William Gibson, ficcionista em torno de quem se move a cyberculture, bastante presente na vida 
americana de hoje.

Em The place of dead roads (1983), romance escrito vinte anos depois da trilogia cut-up, Burroughs toma um caminho inverso ao da science-fiction, realizando um farwest. No corpo de uma narrativa mais inteiriça, menos fragmentada pelas entradas drásticas, puramente experimentais, dos cut-ups, o escritor não fica sem exercitar "hallucinations simples", captando na paisagern do Velho Oeste as fraturas modernas que fundamentam sua viagem pelo tempo. É ao poeta-caminhante de outro continente, de outro século, que ele se reporta, à sondagem de um lugar de origem (a América pioneira, mítica) ou de destinação - como ele empreende aqui, envolvido com o debate sobre a imortalidade/o fim da vida: The place of dead roads, passagem pelas fronteiras modernas/eternas. Um não-lugar estratégico - "the landscape of some forgotten planet" - favorecido pelo deslocamento de sua máquina de escrita e de imagens:

Kim acampou no declive, ao sul, tenda escondida pelas árvores. Ele preparou sua isca com uma grande minhoca púrpura e lançou-a em um dos estreitos e silenciosos córregos, flash amarelo do peixe dentro da água escura.

Ele segurou a casca crocrante do peixe frito pela cabeça e pela cauda, comendo a carne embebida em limonada, sem a espinha.

No crepúsculo, o salto do peixe, uma sinfonia de sapos. Kim viu um imenso sapo conduzindo a orquestra e pensou em "Tarde Histórica", de Rimbaud - "A mão de um maestro desperta o clavecino dos prados... estão jogando cartas no fundo do lago..."

A erva dourada, a sinistra água negra apareciam como a paisagem de algum planeta esquecido. Ele poderia se ver comendo truta ali para sempre, pilhas de ossos com mato crescendo por cima. ${ }^{27}$

\section{ABSTRACT:}

The purpose of this essay is to explore the relationship between Rimbaud's poetry and William Burroughs' experiments with cut-ups. Rimbaud's influence on Burroughs' work, however, extends beyond the cut-ups, KEY WORDS: encompassing his fictional writing.

Modern Poetry, Contemporary Fiction, Influency, Experiment.

REFERENCAS BIBLIOGRÁFICAS:

BURROUGHS, Williom S. The ticker that expladed. Novo York: Grove Press, 1968. The third mind. Novo York: Viking, 1978. - The place of the deod roods. Hovo York. Holt Rineheort, 1983. Os ascritores: as historices entrevistos da Paris Review. Frod. Alberto Alexandre Martins. São Paulo: Componhio das Letros, 1988. p. $131-158$. The job. Now Yort: Penguin, 1989.

- My purpose is to write for spoce age. In: William S. Burroughs of the Front: Critical Reception, 1959-1989. Editodo por Jennie Skerd e Robin Lydenberg. Illinois: Southern Illinois University, 1991.

CANDIDO, Antonio. Rimboud - Ironstusóes. Foltho de Soo Paula, "Letros", p. 1-2, nov. 1991. IYDENBERG, Robin. Word cultures - Rodicol theory and proctice in Williom S. Burroughs fiction. Illinos: Ur

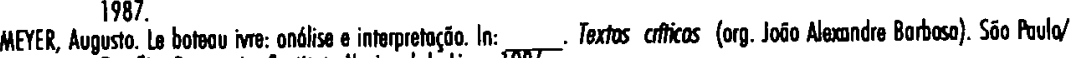

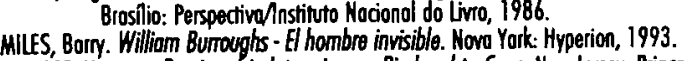

PERLOff, Moriprie. Poetio of indeferminocy - Rimboud to Coge. New Jersey: Princenton University Press, 1981. (1995.

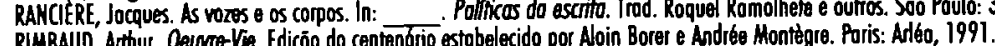

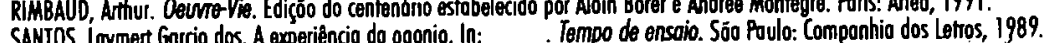

